\title{
Erros de memória e erros de (teorias da) memória
}

Errors of memory and errors of (theory of) memory

\section{Danilo Fraga Dantas}

Resumo: Nesse artigo, investigo três casos de erros de memória obtidos em laboratório como forma de avaliar as principais teorias da memória (declarativa): teoria causal e simulacionismo. De maneira geral, a teoria causal afirma que alguém lembra de algo somente se sua lembrança está numa relação causal adequada com uma experiência anterior daquilo que é lembrado. No simulacionismo, essa relação não é necessária. Os casos de erros de memória investigados são DRM, "perdido no shopping” e erro de conjunção de conteúdo. Esses casos são difíceis para a teoria causal, especialmente em sua versão direta, mas não para o simulacionismo. Minha hipótese é a de que essa dificuldade se deve ao critério causal.

Palavras-chave: Memória episódica; Falsas Lembranças; Confabulação

Abstract: I investigate three lab cases of memory error and test their consequences to the main theories of (declarative) memory: causal theory and simulationism. Roughly, the causal theory states that a subject remembers something only if her remembering is in a causal relation with a past experience of that thing. In simulationism, this relation is not necessary. The cases of memory error are DRM, "lost in the mall", and memoryconjunction error. These are problem cases for the causal theory, but not for simulationism. My hypothesis is that this difficulty is because of the causal requirement.

Keywords: Episodic memory; False Memory; Confabulation

Erros da memória têm um papel importante na psicologia e filosofia da memória. Em psicologia, eles oferecem insights para o estudo do funcionamento normal da memória. Já em filosofia, erros de memória são muitas vezes utilizados como uma forma de testar teorias da memória. Nesse artigo, analiso três casos de erros de memória obtidos em laboratório como forma de avaliar os dois principais tipos de teorias da memória (declarativa):

1. Na teoria causal (Bernecker ${ }^{1}$ e Robins ${ }^{2}$ ), uma lembrança bem-sucedida requer uma representação acurada do que é lembrado, em que a representação está numa conexão causal adequada com uma experiência anterior do que é lembrado.

\footnotetext{
* Doutor pela Universidade da Califórnia, Davis, e pesquisador de estágio pós-doutoral na Universidade Federal de Santa Maria. E-mail: dfdantas@ucdavis.edu

${ }^{1}$ BERNECKER, The Metaphysics of Memory.

${ }^{2}$ ROBINS, Misremembering.
} 
2. No simulacionismo (Michaelian $\left.{ }^{3}\right)$, uma lembrança bem-sucedida requer uma representação acurada do que é lembrado que seja gerada por um processo mnêmico confiável.

Os casos os quais eu vou tratar são: o paradigma Deese-Roediger-McDermott (DRM) (Deese ${ }^{4}$ e Roediger e McDermott ${ }^{5}$ ); experimentos do tipo "perdido no shopping” (Loftus e Pickrell ${ }^{6}$ ) e erros de conjugação de conteúdo (Reinitz et al. ${ }^{7}$ ). Eu investigo como a teoria causal e o simulacionismo classificam esses erros de memória, entre lembrança verídica, lembrança falsídica ou confabulação (falsídica). Argumento que esses casos são problemáticos para a teoria causal, mas não para o simulacionismo e que essa dificuldade se deve ao critério causal.

A discordância entre a teoria causal e o simulacionismo em relação ao critério causal tem consequências para o modo como modelamos o conteúdo do estado mental que acompanha a lembrança. Por isso, essas teorias discordam na descrição de casos de lembranças falsídicas (ex. DRM). Também, é sabido que essas teorias discordam sobre se casos do tipo "perdido no shopping" são de lembrança falsídica ou confabulação (respectivamente). Nessas duas circunstâncias, creio que o simulacionismo se sai melhor, mas que essa discordância não é conclusiva. Porém, creio que a discordância acerca dos casos de erro de conjugação de conteúdo é conclusiva em favor do simulacionismo.

$\mathrm{Na}$ seção 'Preparativos', esclareço alguns pontos sobre o tipo de memória do qual trataremos (memória de indivíduos). Além disso, explicito os pontos centrais da teoria causal e do simulacionismo e reviso como essas teorias distinguem casos de lembrança verídica, lembrança falsídica e confabulação (falsídica). Nas seções seguintes, discuto os casos de DRM, "perdido no shopping” e erro de conjunção de conteúdo. Esses casos são difíceis para a teoria causal (mas não para a teoria simulacionista). Na conclusão, argumento que essa dificuldade se deve ao critério causal.

\section{Preparativos}

A teoria causal e o simulacionismo não tratam da memória em geral, mas da memória declarativa. A distinção mais fundamental entre tipos de memória é aquela entre memória de curta e de longa duração. A memória de curta duração processa a informação por pouco tempo (milissegundos, em alguns casos), enquanto a memória de longa duração trabalha com períodos maiores. A memória de longa duração, por sua vez, é geralmente

\footnotetext{
${ }^{3}$ MICHAELIAN, Mental Time Travel: Episodic Memory and Our Knowledge of the Personal Past.

${ }^{4}$ DEESE. On the Prediction of Occurrence of Certain Verbal Intrusions in Free Recall.

${ }^{5}$ ROEDIGER \& MCDERMOTT. Creating False Memories: Remembering Words Not Presented in Lists.

${ }^{6}$ LOFTUS \& PICKRELL. The Formation of False Memories.

${ }^{7}$ REINITZ, LAMMERS, \& COCHRAN. Memory-Conjunction Errors: Miscombination of Stored Stimulus Features Can Produce Illusions of Memory.
} 
dividida em memória de processos, que é a capacidade de desempenhar capacidades adquiridas (ler, falar, dançar, etc) e memória declarativa, que é a capacidade de recuperar no presente experiências e conhecimentos passados. O conteúdo da memória declarativa pode ser descrito por proposições (daí o nome).

A teoria causal e o simulacionismo tratam da memória declarativa, mas com ênfases diferentes (em 'tipos' diferentes de memória declarativa). A princípio, é possível divisar um relativo consenso sobre a existência de dois tipos gerais de memória declarativa [Tabela 1].

\begin{tabular}{lll}
\hline 'Lembrar de' & 'Lembrar que' & Proposto por \\
\hline $\begin{array}{l}\text { Memória episódica } \\
\text { (experiência autoconsciente) }\end{array}$ & $\begin{array}{l}\text { Memória semântica } \\
\text { (experiência consciente) }\end{array}$ & Tulving ${ }^{8}$ \\
\hline $\begin{array}{l}\text { Memória experiencial } \\
\text { (experiências passadas) }\end{array}$ & $\begin{array}{l}\text { Memória proposicional } \\
\text { (lembrança de que } p \text { é o caso) }\end{array}$ & Malcolm $^{9}$ \\
\hline
\end{tabular}

Tabela 1: Algumas classificações de tipos de memória declarativa ${ }^{10}$.

Apesar da aparente concordância geral, as distinções na Tabela 1 utilizam critérios muito diferentes e, por consequência, apresentam tipos com intensões e mesmo extensões diferentes. Por exemplo, enquanto a distinção entre memória experiencial e proposicional diz respeito ao objeto da lembrança (experiência passada ou proposição) a distinção entre memória episódica e semântica diz respeito ao tipo de experiência envolvida na lembrança:

[Memória episódica] torna possível uma viagem mental através do tempo subjetivo, do presente para o passado, tornando possível, então, que voltemos a experimentar, através de uma consciência autonoética, nossas experiências passadas ${ }^{11}$.

Construções como "viagem no tempo mental” são altamente metafóricas, mas, tanto quanto eu entendo, o que Tulving está defendendo é que uma lembrança episódica envolve uma reconstrução mental (talvez, uma imagem mental) de uma experiência passada. No que se segue, uso 'lembrança' (entre aspas simples) para me referir à experiência fenomênica envolvida numa lembrança episódica. Suponho que essa experiência seja representativa.

Nesse artigo, pretendo tratar na coluna do 'lembrar de'. Apesar de a maioria dos casos de memória episódica ser de casos de 'lembrar de' (e, creio, vice-versa),

\footnotetext{
8 TULVING. Episodic Memory: From Mind to Brain.

${ }^{9}$ MALCOLM. Memory and Mind.

${ }^{10}$ DANTAS. Memória Incerta: Lembranças, Falsas Lembranças e as Ciências da Memória, p. 11.

11 TULVING. Episodic Memory: From Mind to Brain, p. 5.
} 
aparentemente existem casos de memória proposicional que são episódicos ${ }^{12}$. Como quero tratar dos casos não-proposicionais de memória episódica, vou utilizar a noção de memória de indivíduos utilizada por Dantas ${ }^{13}$ e Rebello ${ }^{14}$. A lembrança de um indivíduo é uma lembrança declarativa cujo objeto é um indivíduo concreto, como uma pessoa, um objeto, um evento (evento mental ou não mental), etc.

Como (creio) toda lembrança de um indivíduo é uma lembrança episódica, o foco em memória de indivíduos não deve influenciar a avaliação do simulacionismo (Michaelian trata de memória episódica). No caso da teoria causal, a situação é um pouco diferente. Robins parece tratar de memória episódica, mas Bernecker trata de memória proposicional. Quero deixar claro que as conclusões desse artigo dizem respeito à memória de indivíduos e podem não se aplicar diretamente à memória proposicional (episódica ou não). $\mathrm{Na}$ conclusão, especulo que algumas das características da posição de Bernecker resultam do foco em memória proposicional.

\section{Teoria causal}

A teoria causal afirma que a lembrança de um indivíduo deve estar numa relação causal adequada com uma experiência anterior (ex. percepção) daquele indivíduo. $\mathrm{Na}$ formulação clássica da teoria causal, um sujeito lembra de "uma coisa passada" somente se os seguintes critérios são satisfeitos:

1. Dentro de certos limites de acurácia o sujeito representa a coisa passada.

2. Se a coisa foi pública, então o sujeito observou o que agora a representa. Se foi privada, então ele a experimentou.

3. Sua experiência passada foi operativa em produzir um estado ou uma sucessão de estados no sujeito que são operativos em produzir a sua representação ${ }^{15}$.

A noção de ser "operativa” deve ser entendida como uma relação causal. Critérios semelhantes foram propostos por Bernecker e Robins. Como uma simplificação, suponho que a percepção também envolve uma relação causal e falo livremente da lembrança de um indivíduo como devendo estar numa relação causal com o indivíduo ele mesmo ${ }^{16}$. Robins

\footnotetext{
12 BERNECKER. A Causal Theory of Mnemonic Confabulation, p. 3, nota de rodapé 4.

${ }^{13}$ DANTAS. Memória Incerta: Lembranças, Falsas Lembranças e as Ciências da Memória, p. 15.

${ }^{14}$ REBELLO. Elementos para uma Análise do Recordar.

${ }^{15}$ MARTIN \& DEUTSCHER. Remembering, p. 166, tradução minha.

${ }^{16}$ Se a experiência passada é uma alucinação (uma imaginação, etc), o indivíduo lembrado é um evento mental.
} 
propõe uma taxonomia dos erros de memória que utiliza esses critérios para distinguir entre lembrança verídica, lembrança falsídica e confabulação (falsídica) [Tabela 3] ${ }^{17}$.

\begin{tabular}{lll}
\hline & Acurácia & Critério causal \\
\hline Lembrança Verídica & Sim & Sim \\
\hline Lembrança Falsídica & Não & Sim \\
\hline Confabulação (Falsídica) & Não & Não \\
\hline
\end{tabular}

Tabela 2: Classificação causal para (alguns) erros de memória ${ }^{18}$.

Uma lembrança (verídica) é uma 'lembrança' acurada que está numa relação causal com o indivíduo 'lembrado'. No que se segue, utilizarei outras duas simplificações. A teoria causal tende a tomar a memória como um processo preservativo. Mas, devido ao crescente consenso de que a memória é um processo construtivo ${ }^{19}$, essas teorias tendem a incluir alguma margem de erro para acurácia. Não vou me aprofundar sobre esse ponto. Além disso, a acurácia de uma 'lembrança' é geralmente medida em relação a uma experiência passada do indivíduo 'lembrando'. No que se segue, suponho que a experiência passada é maximamente acurada e trato a acurácia da 'lembrança' diretamente em relação ao indivíduo 'lembrado'.

No contexto da teoria causal, o conteúdo da 'lembrança' de um indivíduo a pode ser modelado da seguinte maneira ${ }^{20}$ :

$$
P_{1} a \& P_{2} a \& \ldots \& P_{\mathrm{n}} a,
$$

em que $P_{1}, P_{2}, \ldots, P_{\mathrm{n}}$ modelam as propriedades (supostamente, do indivíduo lembrado) representadas na 'lembrança'. A que função ' $\&$ ' se refere depende da margem de erro adotada. Se não há qualquer margem de erro, ' $\&$ ' se refere à conjunção da lógica clássica.

A teoria causal tem diferentes implementações. Em sua versão direta, lembrar envolve ter acesso direto ao indivíduo 'lembrado', acesso que seria independente de representações ou inferências ${ }^{21}$. Essa característica é modelada pela presença da constante individual a no conteúdo da 'lembrança', especialmente porque, numa teoria causal dos

\footnotetext{
${ }^{17}$ Existem casos de confabulação verídica (cf. MICHAELIAN. Confabulating, Misremembering, Relearning: The Simulation Theory of Memory and Unsuccessful Remembering, p. 4), mas não vou tratar desses casos.

${ }^{18}$ ROBINS. Mnemonic Confabulation, p. 4.

${ }^{19}$ Cf. SCHACTER \& ADDIS. The Ghosts of Past and Future: A Memory That Works by Piecing Together Bits of The Past May Be Better Suited to Simulating Future Events Than One That Is A Store of Perfect Records.

${ }^{20}$ Não estou afirmando que o conteúdo da 'lembrança' de $a$ tenha essa forma (ex. não estou afirmando que o conteúdo da 'lembrança' de a seja proposicional). Esse é apenas um modelo (muito) simplificado usado para chamar a atenção para as diferenças relevantes entre a teoria causal e o simulacionismo.

${ }^{21}$ BERNECKER, The Metaphysics of Memory, p. 62.
} 
nomes próprios, a se refere diretamente a um indivíduo (independentemente de representações ou inferências $)^{22}$.

Uma lembrança falsídica ocorre quando uma 'lembrança' que está numa relação causal com um indivíduo descreve inacuradamente esse indivíduo. No modelo, há lembrança falsídica quando uma 'lembrança' tem conteúdo $P_{1} a \& P_{2} a \& \ldots \& P_{\mathrm{n}} a$, mas está numa relação causal com um indivíduo $a$ tal que $\neg P_{\mathrm{i}} a$ para um número de $P_{\mathrm{i}}$ 's (dependendo da margem de erro). Robins ${ }^{23}$ cita como exemplos de lembrança falsídica os casos de DRM, em que sujeitos estudam listas de palavras tematicamente relacionadas e 'lembram' de palavras não estudadas.

O termo 'confabulação' foi introduzido no começo do século XX para descrever sintomas de pacientes com síndrome de Korsakoff ${ }^{24}$, mas posteriormente foi utilizado para lidar com um conjunto mais amplo de fenômenos ${ }^{25}$ :

Confabulação é um sintoma que às vezes é encontrado em pacientes amnésicos e consiste na produção involuntária e inconsciente de 'falsa lembranças', que é a lembrança de episódios, que nunca, de fato, aconteceram ou que ocorreram num contexto espaço-temporal diferente daquele referido pelo paciente ${ }^{26}$.

Para a teoria causal, uma confabulação ocorre quando uma 'lembrança' não está numa relação causal com o indivíduo 'lembrado', seja porque esse indivíduo não existe ou porque qualquer convergência entre o indivíduo que causa uma 'lembrança' e o conteúdo dessa 'lembrança' se dá por algum tipo de coincidência. No modelo, uma confabulação ocorre quando uma 'lembrança' cujo conteúdo contém $a$, mas não está numa relação causal $\operatorname{com} a$.

Robins cita como exemplos de confabulação (falsídica) casos do tipo "perdido no shopping”, em que a 'lembrança' não teria "qualquer influência da informação retida do evento passado" 27 . Causalistas tendem a distinguir casos de confabulação 'normal' e de confabulação clínica ${ }^{28}$.

\section{Simulacionismo}

\footnotetext{
${ }^{22} \mathrm{Na}$ Conclusão, discuto a possibilidade de uma teoria causal indireta. Os problemas tratados aqui não são resolvidos por essa modificação.

${ }^{23}$ ROBINS, Misremembering, p. 434.

${ }^{24}$ Cf. BERRIOS. Confabulations: A Conceptual History.

${ }^{25} \mathrm{Nem}$ toda confabulação é sobre o passado e nem toda confabulação envolve erros de memória. Trato aqui de confabulações mnêmicas (que envolvem erros de memória).

${ }^{26}$ DALLA BARBA. Memory, Consciousness and Temporality, p. 28, tradução minha.

${ }^{27}$ ROBINS, Misremembering, p. 434.

${ }^{28}$ ROBINS. Mnemonic Confabulation, p. 9.
} 
No simulacionismo, lembrar é gerar uma representação (“simulação”) mais ou menos semelhante ao indivíduo lembrado (dependendo da margem de erro). Essa simulação pode ser gerada a partir de informações adquiridas durante experiências passadas do sujeito, mas a 'lembrança' não precisa estar causalmente ligada ao indivíduo lembrado em específico.

Michaelian propõe uma taxonomia dos erros de memória utilizando três fatores: acurácia, confiabilidade e internalidade do processo mnêmico [Tabela 4$]^{29}$.

\begin{tabular}{lll}
\hline & Acurácia & Confiabilidade \\
\hline Lembrança Verídica & Sim & Sim \\
\hline Lembrança Falsídica & Não & Sim \\
\hline Confabulação (Falsídica) & Não & Não \\
\hline
\end{tabular}

Tabela 4: Classificação simulacionista para (alguns) erros de memória ${ }^{30}$.

Uma lembrança (verídica) é uma 'lembrança' acurada gerada por um processo mnêmico confiável. Um processo mnêmico é confiável quando tende a gerar simulações acuradas. No que se segue, suponho que o sistema mnêmico humano (sob condições e em funcionamento normais) implementa processos mnêmicos confiáveis. Por isso, falo em sistemas mnêmicos confiáveis.

No simulacionismo, acurácia funciona mais ou menos como na teoria causal. Porém, o modo como o simulacionismo descreve o funcionamento da memória tem consequências para o modo como o conteúdo da 'lembrança' deve ser modelado. Diferentemente da teoria causal, o simulacionismo não requer que a 'lembrança' de um indivíduo esteja causalmente ligada a esse indivíduo em específico. Por isso, a maneira simulacionista de modelar o conteúdo da 'lembrança' não usa constantes individuais, tais como $a, b, c$, mas a quantificação existencial individual de Whitehead e Russell ${ }^{31}$, que utiliza o símbolo ' ' para formalizar descrições definidas. O conteúdo da 'lembrança' deve ser modelado da seguinte maneira:

$$
1 x\left(P_{1} x \& P_{2} x \& \ldots \& P_{\mathrm{n}} x\right)
$$

\footnotetext{
${ }^{29}$ Não vou tratar desse terceiro parâmetro porque ele se destina a distinguir casos de reaprendizado de casos de lembranças (verídicas e falsídicas) e confabulação (verídica e falsídica).

30 MICHAELIAN. Confabulating, Misremembering, Relearning: The Simulation Theory of Memory and Unsuccessful Remembering, p. 8.

${ }^{31}$ WHITEHEAD \& RUSSELL. Principia Mathematica.
} 
em que o quantificador $x$ deve ser lido como 'o $x$ tal que'. A expressão $x(P x)$ é equivalente a $\exists x(P x \wedge \forall y(P y \rightarrow x=y))$. Ou seja, a lembrança é sobre 'o $x$ ', qualquer que seja, que tenha sido experienciado anteriormente pelo sujeito e que tenha as propriedades representadas por $P_{1}, P_{2}, \ldots, P_{\mathrm{n}}$ (considerando a margem de erro).

Esse modelo está de acordo com o fato de que simulacionistas tendem a defender uma teoria indireta da memória (ex. Michaelian). O uso de descrições definidas para modelar o caráter indireto dessa teoria é adequado porque o significado de uma descrição pode ser explicado sem mencionar indivíduos (nem mesmo o indivíduo, se há um e somente um, que satisfaz a descrição). O conteúdo $1 x\left(P_{1} x \& P_{2} X \& \ldots\right.$ \& $\left.P_{\mathrm{n}} x\right)$ não nos dá qualquer acesso direto a qualquer indivíduo. Na conclusão, avalio a teoria causal indireta à luz dos casos discutidos.

Uma lembrança falsídica ocorre quando uma 'lembrança' gerada por um sistema confiável tem um conteúdo do tipo $1 x\left(P_{1} x \& P_{2} \chi \& \ldots \& P_{\mathrm{n}} x\right)$, mas ou (i) não há um $x$ que tenha sido experieciado no passado e tenha as propriedades representadas por $P_{1}, P_{2}, \ldots, P_{\mathrm{n}}$ ou (ii) há mais de um $x$ experieciado no passado que tenha as propriedades $P_{1}, P_{2}, \ldots, P_{n}$ (considerando a margem de erro). Nesse último caso (que é mais intrigante), o sujeito talvez lembre de todos os indivíduos que cumprem a descrição, mas essa lembrança seria falsídica porque seu conteúdo da representaria os indivíduos lembrados como sendo um e o mesmo ('o $x$ tal que').

Para Michaelian, tanto os casos de DRM quanto os de "perdido no shopping” são casos de lembrança falsídica. Ou seja, há uma discordância entre a teoria causal e o simulacionismo em relação a se casos de "perdido no shopping” são de confabulação (falsídica) ou lembrança falsídica (respectivamente). Para a teoria simulacionista, uma confabulação ocorre quando uma 'lembrança' é gerada por um sistema mnêmico não confiável, ou seja, um sistema que tende a gerar simulações inacuradas de indivíduos. No simulacionismo, “confabulação' diz respeito principalmente aos casos de confabulação clínica, o que está de acordo com o uso inicial do termo.

\section{Caso 1: Deese-Roediger-Mcdermott (DRM)}

Robins cita como exemplos paradigmáticos de lembrança falsídica os casos de DRM. Michaelian concorda com esse diagnóstico.

O paradigma DRM é composto de duas fases. $\mathrm{Na}$ primeira fase, os experimentadores apresentam aos participantes listas de palavras semanticamente relacionadas. Na segunda fase, os experimentadores pedem que os participantes lembrem tantas palavras apresentadas na primeira fase quanto eles conseguirem. O resultado típico é que participantes 'lembrem' de uma palavra-isca ("lure”), que não foi estudada na 
primeira fase, mas que serve de um tipo de foco semântico da lista. Esse é um exemplo de lista apresentada por Roediger e McDermott ${ }^{32}$, em que 'king' é a isca:

(King) queen, England, crown, prince, George, dictator, palace, throne, chess, rule, subjects, monarch, royal, leader, reign.

\section{Teoria causal}

Para a teoria causal, casos de DRM são de lembrança falsídica. Sendo assim, estes devem ser casos de 'lembranças' inacuradas que cumprem o critério causal. A descrição mais natural dos casos de DRM seria a de que as palavras estudadas na primeira fase causam a 'lembrança' da isca na segunda (talvez, por causa das propriedades semânticas em comum). No modelo, a 'lembrança' teria conteúdo $P_{1} a \& P_{2} a \& \ldots \& P_{\mathrm{n}} a$, em que $a$ se refere à isca e $P_{1}, P_{2}, \ldots, P_{\mathrm{n}}$ representam a suas propriedades fonéticas, morfológicas, semânticas, etc. Essa descrição não está disponível para a teoria causal porque uma lembrança falsídica da isca precisaria ser causada pela isca ela mesmo e não pelas palavras estudadas na primeira fase.

Uma alternativa para a teoria causal seria tomar o conteúdo da lembrança como sendo sobre a lista de palavras como um todo: $P_{1} a \& P_{2} a \& \ldots \& P_{\mathrm{n}} a$, em que $a$ se refere a uma lista de palavras e $P_{1}, P_{2}, \ldots, P_{\mathrm{n}}$ individuam as palavras que compõem a lista (talvez, representando propriedades que individuem a primeira, segunda, etc palavra da lista e também a isca). Nesse caso, a lembrança seria causada pela lista estudada na primeira fase, mas teria um conteúdo inacurado porque $\neg P_{\mathrm{i}} a$ para as propriedades que individuam a isca como parte da lista.

Essa descrição é problemática porque os participantes do estudo relatam lembrar não apenas das palavras estudadas, mas também do evento do estudo de cada palavra em específico.

Os participantes confiantemente relembraram e reconheceram palavras que não foram apresentadas e também reportaram lembrar a ocorrência desses eventos $^{33}$.

A descrição da teoria causal trataria os eventos de estudo de cada palavra como propriedades do evento geral de estudo da lista. Porém, a relação entre esses eventos é de parte-todo (ex. a extensão espaço-temporal de cada um dos eventos específicos está contida na do evento geral) e não uns sendo aspectos de outros. O estudo de cada palavra é um indivíduo concreto (um evento) e não uma propriedade (propriedade são às vezes tomadas como universais abstratos) do evento geral de estudo da lista.

\footnotetext{
${ }^{32}$ ROEDIGER \& MCDERMOTT. Creating False Memories: Remembering Words Not Presented in Lists, p. 814.

${ }^{33}$ Idem, p. 812, com tradução e ênfase minha.
} 
Restam duas estratégias para a teoria causal:

- Erro de atribuição de coordenada espaço-temporal;

- Erro de monitoramento de fonte.

A estratégia do erro de atribuição de coordenada espaço-temporal consiste em tomar o conteúdo da 'lembrança' como sendo, de fato, sobre a isca e tomar uma experiência anterior qualquer da isca como sendo a causa da 'lembrança' (ex. a leitura da isca num livro qualquer). Nesse caso, a lembrança seria falsídica porque seu conteúdo representaria a isca como tendo sido estudada na primeira fase. Essa descrição é artificial porque apela para um evento indeterminado de estudo da isca. Porém, essa artificialidade não me parece ser evidência conclusiva contra a teoria causal, especialmente porque essa estratégia pode ser aplicada mais naturalmente a casos próximos aos de DRM ${ }^{34}$.

A estratégia do erro de monitoramento de fonte ${ }^{35}$ consiste em tomar o conteúdo da 'lembrança' como sendo, de fato, sobre a isca e tomar uma imaginação anterior da isca como sendo a causa da 'lembrança'. A imaginação da isca poderia ter ocorrido, por exemplo, durante a primeira fase do experimento (ex. suscitada pelas propriedades semânticas das palavras estudadas). Nesse caso, a lembrança seria falsídica porque seu conteúdo representaria a isca como tendo sido estudada (e não meramente imaginada). Essa explicação me parece mais natural porque não depende da suposição de um evento indeterminado de estudo da isca. Além disso, essa estratégia é suportada por evidência empírica ${ }^{36}$.

\footnotetext{
${ }^{34}$ Em 1992, o então candidato à presidência dos EUA, Ross Perot desistiu da concorrência, que chegou a liderar com 39\%. Poucos dias depois, Levine (cf. LEVINE. Reconstructing Memory for Emotions) entrevistou 227 correligionários de Perot, para saber como eles se sentiam sobre a desistência de seu candidato. Em outubro daquele mesmo ano, Perot resolveu voltar à disputa e terminou as eleições com $18 \%$ dos votos. Após o final das eleições, Levine pediu a 147 dos correligionários entrevistados anteriormente que eles lembrassem de como eles se sentiam em julho e que relatassem também seus sentimentos atuais sobre o tema. A conclusão foi que os correligionários que voltaram à campanha 'lembraram' de sentir menos raiva do que sentiram, enquanto os que abandonaram definitivamente a campanha 'lembraram' de ter menos esperança do que tiveram. Para explicar seus dados, Levine afirma que o que os participantes 'lembravam' de sentir era influenciado pelo que eles sentiam no presente. Ou seja, os participantes 'lembraram' de um sentimento que tiveram no passado próximo, mas localizaram erradamente esse sentimento no tempo.

${ }^{35}$ Cf. JOHNSON, HASHTROUDI, \& LINDSAY. Source Monitoring. Psychological Bulletin.

${ }^{36}$ Johnson et al. (JOHNSON, RAYE, WANG, \& TAYLOR. Fact and Fantasy: The Roles of Accuracy and Variability) pediram que os participantes contassem quantas vezes eles viram e quantas vezes imaginaram uma determinada figura. Os experimentadores, então, variaram o número de vezes em que a figura era mostrada e o número de vezes em que pediam aos participantes que eles imaginassem a figura. Os pesquisadores concluíram que, quanto mais era pedido que os participantes imaginassem a figura, maior era o número de vezes em que eles estimavam tê-la visto.
} 


\section{Simulacionismo}

O diagnóstico simulacionista para os casos DRM é idêntico ao da teoria causal: lembrança falsídica. Porém, creio que a descrição simulacionista para os casos DRM é mais simples e natural que qualquer uma das descrições causais.

Se casos de DRM são de lembrança falsídica, esses casos devem ser de 'lembranças' inacuradas geradas por um sistema mnêmico confiável. O conteúdo da 'lembrança' da isca seria algo do tipo $1 x\left(P_{1} x \& P_{2} x \& \ldots \& P_{\mathrm{n}} x\right)$ em que $P_{1}, P_{2}, \ldots, P_{\mathrm{n}}$ representariam propriedades (fonéticas, morfológicas, semânticas, etc) da isca, bem como a propriedade de ter sido estudada na primeira fase. Como nenhuma das palavras estudadas na primeira fase tem as propriedades fonéticas, morfológicas, semânticas, etc da isca e a isca não foi estudada na primeira fase, o conteúdo da lembrança é inacurado. Por outro lado, casos de DRM ocorrem em sistemas mnêmicos humanos sob condições e em funcionamento normais ${ }^{37}$.

\section{Caso 2: perdido no shopping}

Robins cita como exemplos paradigmáticos de confabulação (falsídica) os casos do tipo “perdido no shopping”. Michaelian não concorda com esse diagnóstico. Para os simulacionistas, casos de "perdido no shopping” são de lembrança falsídica.

Loftus e Pickrell ${ }^{38}$ recrutaram 24 pares de parentes, com idades entre 18 e 53 anos. Os parentes mais velhos relataram aos mais novos quatro histórias sobre eventos da infância dos mais novos (três das histórias eram verdadeiras, enquanto uma era sobre o evento não ocorrido em que o parente mais novo se perdia num shopping). Os experimentadores pediram, então, que os parentes mais novos 'lembrassem' dos quatro eventos (em duas entrevistas, realizadas entre duas e quatro semanas depois de eles terem estudado as histórias). $\mathrm{Na}$ aplicação mais famosa do paradigma ${ }^{39}$, Chris, um garoto de 14 anos, foi informado por seu irmão mais velho, Jim, que, quando ele (Chris) tinha 5 anos, ele havia se perdido num shopping na cidade de Spokane, Washington, onde sua família fazia compras, e que ele estava chorando bastante quando foi resgatado por um homem idoso e então reunido a sua família. Nos dias seguintes, Chris 'lembrou' de mais e mais detalhes sobre quando se perdeu no shopping. Ele 'lembrou' que o homem que o resgatou era

\footnotetext{
37 O efeito DRM tem sido replicado extensivamente e pode ser obtido a partir de diferentes formas de similaridade (categórica, fonológica, ortográfica); tipos de estímulo (figura, faces, matrizes de ponto); intervalos entre as fases de estudo e reconhecimento (horas, dias, meses), etc. Cf. ROBINS, Misremembering, p. 434.

${ }^{38}$ LOFTUS \& PICKRELL. The Formation of False Memories, p. 721.

${ }^{39}$ LOFTUS, COAN, \& PICKRELL. Manufacturing False Memories Using Bits of Reality.
} 
“muito bacana”. 'Lembrou' de ter ficado com muito medo de nunca mais ver sua família novamente. E 'lembrou' de sua mãe ter ficado zangada com ele.

\section{Teoria causal}

Para a teoria causal, casos de "perdido no shopping" são casos de confabulação (falsídica). Sendo assim, casos de "perdido no shopping” devem ser casos de 'lembranças' inacuradas que não cumprem o critério causal. Existe uma descrição natural disponível para a teoria causal em que esse é o caso. O conteúdo da 'lembrança' de Chris seria algo do tipo $P_{1} a \& P_{2} a \& \ldots \& P_{\mathrm{n}} a$, em que $a$ se refere ao evento em que Chris se perdeu num shopping em Spokane aos cinco anos, etc e $P_{1}, P_{2}, \ldots, P_{\mathrm{n}}$ representam as propriedades desse evento. Como esse evento não ocorreu, ele não poderia ter causado a 'lembrança' de Chris. Além disso, como esse evento não ocorreu, ele não poderia ter as propriedades representadas por $P_{1}, P_{2}, \ldots, P_{\mathrm{n}}$. Apesar de haver um problema na interpretação de $\neg P_{\mathrm{i}} a$ numa teoria causal dos nomes próprios, essa descrição me parece natural.

Porém, se a estratégia do erro de monitoramento de fonte está disponível para casos de DRM, a mesma estratégia poderia ser utilizada para casos de "perdido no shopping”. De fato, é essa a descrição defendida por Loftus e Pickrell:

O desenvolvimento da falsa lembrança de ter se perdido no shopping pode ter evoluído primeiramente quando uma mera sugestão de ter se perdido deixa um traço de memória no cérebro. Mesmo se essa informação tenha sido originalmente rotulada como uma sugestão em vez de um fato histórico... enquanto o tempo passa o rótulo que indica que ter se perdido no shopping era uma mera sugestão se deteriora. ... Agora, você 'lembra' de ter se perdido no shopping quando criança ${ }^{40}$.

Nesse caso, porém, a 'lembrança' de Chris seria uma lembrança falsídica (e não uma confabulação). O conteúdo da lembrança seria algo do tipo $P_{1} a \& P_{2} a \& \ldots$ \& $P_{\mathrm{n}} a$, em que $a$ se refere a um evento imaginado (provavelmente, enquanto Jim descrevia o caso) e $P_{1}, P_{2}, \ldots$, $P_{\mathrm{n}}$ representam as propriedades desse evento, além da propriedade de ter ocorrido no passado de Chris. O conteúdo da 'lembrança' seria inacurado porque o evento imaginado não ocorreu no passado de Chris. Porém, a 'lembrança' de Chris teria sido causada pelo evento imaginado. Para evitar essa possibilidade, uma opção é limitar o critério causal de modo que apenas eventos concretos (não-imaginários) possam causar lembranças. Mas, nesse caso, a estratégia do erro de monitoramento de fonte não estaria disponível para os casos de DRM, onde ela é a estratégia mais natural disponível.

Essa dificuldade não é conclusiva contra a teoria causal. Há a possibilidade de limitar o critério causal de modo que apenas eventos concretos possam causar lembranças

${ }^{40}$ LOFTUS \& PICKRELL. The Formation of False Memories, P. 724, tradução minha. 
(barrando a estratégia do erro de monitoramento de fonte), utilizar a estratégia do erro de atribuição de coordenada espaço-temporal para descrever os casos de DRM e utilizar a estratégia natural para escrever os casos de "perdido no shopping" - mantendo, assim, os diagnósticos de Robins. Porém, essa solução implica sustentar uma descrição artificial para os casos de DRM e barrar a estratégia de monitoramento de fonte, que, além de ser a descrição preferida por Loftus e Pickrell, é amplamente estudada e aplicada na literatura ${ }^{41}$.

\section{Simulacionismo}

O diagnóstico da teoria simulacionista para casos de "perdidos no shopping" é de lembrança falsídica. O conteúdo da 'lembrança' de Chris seria algo do tipo $1 x\left(P_{1} x \& P_{2} x \&\right.$... $\left.\& P_{\mathrm{n}} x\right)$ em que $P_{1}, P_{2}, \ldots, P_{\mathrm{n}}$ representariam propriedades do evento em que Chris se perdeu num shopping em Spokane aos cinco anos, etc (incluindo a propriedade de ter ocorrido no passado de Chris). Como não há um evento com essas propriedades que tenha ocorrido no passado de Chris, o conteúdo da 'lembrança' é inacurado. Por outro lado, erros do tipo "perdido no shopping" ocorrem em sistemas mnêmicos humanos sob condições e em funcionamento normais ${ }^{42}$.

Uma diferença entre casos de "perdido no shopping” e os casos paradigmáticos de confabulação clínica é que esses últimos ocorrem por falha no sistema mnêmico. Por outro lado, utilizando a estratégia do erro de monitoramento de fonte, os casos de "perdido no shopping” não envolveriam erros do sistema mnêmico, mas apenas erros de julgamento ${ }^{43}$ :

Nos casos de "perdido no shopping", quando o sujeito imagina inicialmente um evento, ele constrói uma representação de um evento que ele não experienciou, mas ele não está tentando construir uma representação de um evento que ele experienciou. Aqui, inacurácia não resulta do erro e a questão do mal funcionamento não se coloca. Em casos de confabulação clínica, em contraste, quando o sujeito imagina inicialmente o evento, ele constrói uma representação de um evento que ele não experienciou, mas ele está tentando construir uma representação de um evento que ele

\footnotetext{
${ }^{41}$ Ex. JOHNSON, FOLEY, \& LEACH. The Consequences for Memory of Imagining in Another Person's Voice.

${ }^{42}$ Por exemplo, a testemunha de um crime pode afirmar reconhecer a face de um indivíduo quando ela, de fato, viu diferentes faces que, em conjunto, têm as características da face do acusado. Brown et al. (cf. BROWN, DEFFENBACHER, \& STURGILL. Memory for Faces and the Circumstances of Encounter) testou essa possibilidade em condições mais próximas das ecológicas.

${ }^{43}$ Michaelian (MICHAELIAN. Confabulating, Misremembering, Relearning: The Simulation Theory of Memory and Unsuccessful Remembering, p. 6) discute melhor esse ponto. Para ele, há uma diferença entre casos de DRM e de "perdidos no shopping", porém essa diferença não implica classificar uns como lembranças falsídicas e outros como confabulação (falsídica).
} 
experienciou. Aqui, inacurácia resulta de erro e o erro se deve a mal funcionamento [do sistema mnêmico $]^{44}$.

No geral, teoria causal e o simulacionismo discordam acerca de erros de monitoramento de fonte. Para causalistas, esses são casos de confabulação; para simulacionistas, esses são casos de lembrança (geralmente, falsídica). A diferença de diagnóstico se deve, em parte, à noção de 'confabulação' adotada. Para simulacionistas, 'confabulação' se aplica mais diretamente aos casos clínicos, enquanto causalistas insistem num uso mais amplo do termo. Por esse motivo, penso que a diferença de diagnóstico em relação aos casos de 'perdido no shopping' não é evidência conclusiva a favor de uma ou outra teoria. É plausível descrever esses casos como lembrança falsídica quando ou confabulação, na noção mais ampla de 'confabulação' causalista.

\section{Caso 3: erro de conjunção de conteúdo}

Num caso típico de erro de conjunção de conteúdo, um sujeito experiencia dois itens “aparentados” e tem uma 'lembrança' cujo conteúdo é construído a partir de elementos dos dois itens estudados.

O experimento 6 de Reinitz et al $^{45}$ testou o fenômeno dos erros de conjunção de conteúdo utilizando imagens de faces. Reinitz et al. testaram 48 participantes usando desenhos simples de faces humanas construídos a partir de um "identikit" produzido pelos experimentadores. $\mathrm{Na}$ fase de estudo, os experimentadores apresentaram para cada participante seis faces humanas selecionadas aleatoriamente, uma de cada vez, por 30 segundos cada. Depois da fase de estudo, os experimentadores apresentaram aos participantes oitos estímulos para a fase de reconhecimento: duas faces estudadas anteriormente (estímulo de tipo 1); duas faces construídas a partir de características de outras duas faces estudadas anteriormente (tipo 2); duas faces construídas a partir de características de uma face estudada anteriormente e características novas (tipo 3) e duas faces completamente novas (tipo 4). Os participantes responderam 'sim' ou 'não' à questão 'essa face foi estudada anteriormente?'. A frequência relativa de resposta 'sim' para estímulos de tipo 1, 2, 3 e 4 foram de 0,71, 0,52, 0,19 e 0,13 (respectivamente). Chamarei os últimos três casos de erros de tipo 2,3 e 4 (respectivamente).

\footnotetext{
44 MICHAELIAN. Confabulating, Misremembering, Relearning: The Simulation Theory of Memory and Unsuccessful Remembering, p. 7, tradução minha.

45 REINITZ, LAMMERS, \& COCHRAN. Memory-Conjunction Errors: Miscombination of Stored Stimulus Features Can Produce Illusions of Memory, p. 8.
} 


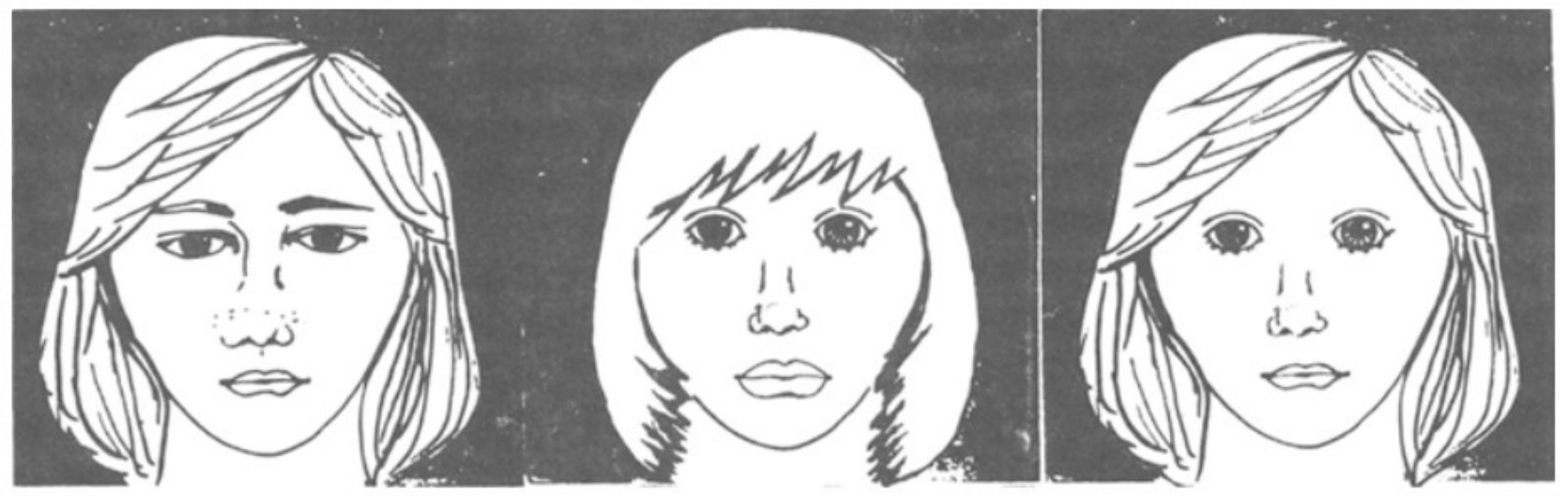

Figura 1: Caso de erro de conjunção de conteúdo. Depois estudar as duas primeiras faces (mas não a terceira), $52 \%$ dos participantes 'lembram' da terceira. Erro do tipo $2^{46}$.

Suponha que Reinitz et al. tenham apresentado ao participante $S$ as duas primeiras faces da Figura 1 e perguntado se ele 'lembrava' da terceira. No que se segue, chamamos a primeira face de $a$, a segunda de $b$ e a terceira de $c$. A face $c$ é composta pela conjunção em proporções iguais de características de a (cabelos soltos, orelhas cobertas, boca fechada, etc) e $b$ (sobrancelhas finas, olhos arredondados, nariz pequeno, etc).

\section{Teoria causal}

Suponha que o diagnóstico da teoria causal para os casos de erro de conjunção de conteúdo seja de lembrança falsídica. Se esse é o caso, a 'lembrança' de $S$ deve ser inacurada, apesar de ser sobre indivíduo que está numa relação causal com essa 'lembrança'. Nesse caso, há duas possibilidades de descrição do conteúdo da 'lembrança' de $S$ disponíveis ao causalista:

$$
P_{1} a \& P_{2} a \& \ldots \& P_{\mathrm{n}} a
$$

e

\section{$P_{1} b \& P_{2} b \& \ldots \& P_{\mathrm{n}} b$.}

Em ambos os casos, teríamos uma lembrança falsídica. Supondo que $P_{1}, P_{2}, \ldots, P_{\mathrm{m}}$ são acuradas em relação $a$ (mas não a $b$ ) e $P_{\mathrm{m}+1}, P_{\mathrm{m}+2}, \ldots, P_{\mathrm{n}}$ são acuradas em relação a $b$ (mas não a $a)$, teríamos (respectivamente) uma lembrança causada por a mas que descreve inacuradamente $a$ e uma lembrança causada por $b$ mas que descreve inacuradamente $b$. Porém, não há maneira razoável de decidir qual dessas fórmulas descreve o conteúdo da 'lembrança' (supondo que $n=2 m$ ).

Porém, casos de erro de conjunção de conteúdo levantam um problema mais sério para a teoria causal. Se as fórmulas acima são indistinguíveis enquanto descrições do

${ }^{46}$ Idem, p. 6. 
conteúdo da 'lembrança', esse não é o caso quando o critério causal é levado em consideração. No primeiro caso, a 'lembrança' seria causalmente dependente de $a$ (mas não de $b$ ); no segundo caso, a 'lembrança' seria causalmente dependente de $b$ (mas não de $a$ ). Porém, a 'lembrança' de $S$ parece ser causalmente dependente tanto de $a$ quanto de $b$. De fato, a explicação de Reinitz et al. para seus resultados explora essa dupla dependência causal:

Os resultados, portanto, nos dão forte evidência contra qualquer modelo que propõe que evocação envolva a ativação de um traço de memória único que representa o estímulo previamente experienciado ${ }^{47}$.

Bernecker ${ }^{48}$ define o critério causal como uma noção contrafactual: a 'lembrança' que um sujeito $S$ tem de um indivíduo $a$ é causada por uma experiência anterior que $S$ tem de $a$ sse se fosse o caso de $S$ não ter experienciado $a$ anteriormente, então $S$ não teria 'lembrado' de a. Na teoria “clássica” dos contrafactuais (cf. Lewis"4), um contrafactual é verdadeiro quando seu consequente é verdadeiro em todos os mundos possíveis maximamente similares ao mundo atual em que seu antecedente o é. Nesse caso, nem a experiência de $a$, nem a experiência de $b$ causariam a 'lembrança' que $S$ tem de $c$ porque, em $19 \%$ dos mundos possíveis maximamente similares ao mundo atual ${ }^{50}, S$ 'lembra' de $c$ mesmo não havendo experienciado $a$ (alternativamente, $b$ ) na primeira fase do estudo ${ }^{51}$. Bernecker ${ }^{52}$ aceita a análise clássica dos contrafactuais. Para lidar com esses casos, é necessária alguma noção probabilística de causalidade (ex. Reichenbach ${ }^{53}$ ), já que o (não) estudo de $a$ e $b$ apenas modifica a probabilidade da 'lembrança' de $c$, não determinando se essa 'lembrança' acontece ou não.

Porém, nesse caso o problema é outro: é difícil expressar a dupla dependência causal no conteúdo da lembrança. Uma maneira de fazê-lo seria a seguinte:

\footnotetext{
${ }^{47}$ Idem, p. 9, tradução minha.

${ }^{48}$ BERNECKER. A Causal Theory of Mnemonic Confabulation, p. 9.

${ }^{49}$ LEWIS. Counterfactuals. próximos, generalizações nômicas são mantidas intactas. estudo.

52 BERNECKER. Memory: A Philosophical Study, p. 98.

${ }^{53}$ REICHENBACH. The Direction of Time.
}

50 Esse é o caso, por exemplo, se utilizamos o critério de similaridade "clássico", proposto por Lewis (cf. LEWIS. Counterfactual Dependence and Time’s Arrow, p. 472), já que, dado esse critério, nos mundos possíveis

${ }^{51}$ Estou tomando os resultados de Reinitz et al. como expressando a frequência em que um sistema mnêmico humano normal comete esses erros. No caso específico, refiro-me aos erros do tipo 3, em que participantes 'lembram’ de faces compostas por algumas características de faces estudadas e outras características nãoestudadas (frequência de 0,19). Também estou supondo que há uma relação entre probabilidade e mundos possíveis próximos e que probabilidades expressam proporções desses mundos. Por isso, interpreto o resultado do experimento como implicando que 19\% dos mundos possíveis maximamente similares ao mundo atual, S 'lembra' de c mesmo não havendo experienciado a (alternativamente, b) na primeira fase do 


$$
P_{1} c \& P_{2} c \& \ldots \& P_{\mathrm{n}} c \& c=a \& c=b
$$

Nesse caso, o conteúdo da 'lembrança' de $S$ resulta, de fato, inacurado. Não existe tal $c$ concreto tal que $P_{1} c \& P_{2} c \& \ldots \& P_{n} c \& c=a \& c=b$, especialmente por causa da parte que afirma que $c=a$ e $c=b$. Porém, se estamos assumindo que um $c$ imaginário não pode causar lembranças (verídicas ou falsídicas), o critério causal não é satisfeito. Nesse caso, o diagnóstico da teoria causal para casos de erro de conjunção de conteúdo seria de confabulação (falsídica). Não consigo pensar numa representação do conteúdo da 'lembrança' que resulte noutro diagnóstico.

Não me parece razoável tomar casos de erro de conjunção de conteúdo como casos de confabulação (mesmo na noção causalista de 'confabulação'). A noção causalista de 'confabulação' diz respeito a 'lembranças' que falham em estar ancoradas na experiência passada do sujeito. Mas casos de erro de conjunção de conteúdo são ancoradas na experiência passada do sujeito (no estudo de $a$ e $b$ ). Uma maneira de expressar esse problema é o seguinte: se $S$ não tivesse aprendido a face $b$ (alternativamente, a face $a$ ) na primeira fase do estudo, a teoria causal teria descrito a 'lembrança' de S como lembrança falsídica ${ }^{54}$. Além disso, se $c$ fosse composto de mais propriedades de $a$ (alternativamente, de b), haveria razão para escolher a primeira fórmula (alternativamente, a segunda) e, novamente, o diagnóstico da teoria causal seria de lembrança falsídica. Não me parece razoável supor que ter visto mais faces na primeira fase do estudo (ou a composição da terceira face ser levemente diferente) transforme uma lembrança falsísica numa confabulação (falsídica), mesmo na noção causalista de 'confabulação’.

\section{Simulacionismo}

O diagnóstico simulacionista para casos de erro de conjunção de conteúdo é de lembrança falsídica. O conteúdo da 'lembrança' de $S$ seria algo do tipo $1 x\left(P_{1} x \& P_{2} x \&\right.$... \& $\left.P_{\mathrm{n}} X\right)$, em que os predicados $P_{1}, P_{2}, \ldots, P_{\mathrm{n}}$ representariam propriedades da face 'lembrada'. Não existe 'o $x$ ' tal que $P_{1} \chi, P_{2} \chi, \ldots, P_{\mathrm{n}} \chi^{55}$. Por isso, o conteúdo da 'lembrança' seria inacurado. Por outro lado, os erros de conjunção de conteúdo ocorrem em sistemas mnêmicos humanos sob condições e em funcionamento normais.

\footnotetext{
${ }^{54} \mathrm{O}$ conteúdo da 'lembrança' de $S$ seria $P 1 a \& P 2 a \&$... \& Pna, em que, para metade dos $P \mathrm{i}, \neg P \mathrm{i} a$ (inacurado), porém a 'lembrança' seria inequivocadamente causada por $a$.

${ }^{55}$ No caso de a margem de erro permitida ser muito alta, há dois indivíduos que satisfazem essa descrição ( $a$ e b). No caso de a margem de erro ser mais baixa, não há nenhum. Em ambos os casos, o conteúdo é inacurado.
} 


\section{Conclusão}

A principal diferença entre a teoria causal e o simulacionismo é o critério causal: no causalismo, a lembrança de um indivíduo deve estar numa relação causal como o indivíduo em questão; no simulacionismo, não é necessário que essa relação causal exista. Nesse artigo, defendi que essa diferença tem consequências para o modo como a teoria causal (especialmente, em sua versão direta) e o simulacionismo descrevem o conteúdo da 'lembrança' de um indivíduo.

Nos casos de DRM, as teorias concordam no diagnóstico de lembrança falsídica. Porém, enquanto o diagnóstico do simulacionismo é único e natural, há diferentes maneiras de descrever esses casos na teoria causal (e as maneiras que retornam o diagnóstico desejado não são naturais). Nos casos de "perdido no shopping”, as teorias discordam. O diagnóstico simulacionista (consistente com o anterior) é de lembrança falsídica. O diagnóstico (pretendido pelo) causalista é o de confabulação. Mas, para obter esse diagnóstico, a teoria causal precisa barrar a estratégia de erro de monitoramento de fonte, que, além de ser uma das estratégias que retornam o diagnóstico desejado para os casos de DRM, é o diagnóstico utilizado por Loftus e Pickrell para descrever seus resultados.

A discordância entre a teoria causal e simulacionismo sobre se os casos de "perdido no shopping” são de confabulação (falsídica) ou lembrança falsídica (respectivamente) não é evidência conclusiva para uma ou outra teoria, já que estas supõem noções diferentes de 'confabulação'. O mesmo não acontece em relação aos casos de erro de conjunção de conteúdo. O diagnóstico simulacionista (consistente com os anteriores) é de lembrança falsídica. Qual seja o diagnóstico causalista é uma questão complicada. Se o diagnóstico é de lembrança falsídica, então a teoria causal prevê duas descrições diferentes, mas indecidíveis, do conteúdo da 'lembrança'. A outra opção acaba sendo um diagnóstico de confabulação. Porém, esse diagnóstico não me parece consistente com a noção causalista de 'confabulação'.

Os problemas relatados nesse artigo talvez não tenham passado pela cabeça de Bernecker pelo motivo de ele estar diretamente interessado em memória proposicional. No caso da memória proposicional, não há relação direta entre o conteúdo da 'lembrança' e o evento de aprendizado anterior. Por exemplo, se eu lembro (episodicamente) que Cabral “descobriu” o Brasil, o conteúdo dessa 'lembrança' não está diretamente relacionado ao evento em que aprendi esse fato (provavelmente, na escola primária). Mas o caso é diferente para a memória de indivíduos, em que o conteúdo da 'lembrança' de a precisaria estar causalmente relacionado a uma experiência anterior de $a$. Robins, por outro lado, não trata de memória proposicional. 
Enquanto Bernecker adota expressamente uma teoria direta da memória, Robins não o faz. A princípio, seria possível pensar numa teoria causal indireta em que o conteúdo da 'lembrança' é tal qual o do simulacionismo:

$$
1 x\left(P_{1} x \& P_{2} x \& \ldots \& P_{\mathrm{n}} x\right)
$$

A diferença entre uma teoria causal indireta e o simulacionismo é que, na primeira teoria (mas não na segunda), 'o $x$ ' tal que $P_{1} x \& P_{2} x \& \ldots \& P_{\mathrm{n}} x$ deve ser a causa da 'lembrança'.

Essa modificação não resolve nossos problemas. Nos casos de DRM, a explicação mais natural continua não funcionando. As palavras estudadas continuam não podendo ser a causa da 'lembrança'. Restam a estratégia do erro de atribuição de coordenada espaçotemporal e a estratégia de erro de monitoramento de fonte. Porém, essa última estratégia deve ser barrada, caso contrário os casos de "perdido no shopping" não seriam casos de confabulação. Até aqui, a situação da teoria causal indireta é estritamente paralela à da teoria causal direta.

Nos casos de erro de conjunção de conteúdo, a situação da teoria causal indireta é, num certo sentido, pior que a da teoria causal direta, já que a teoria causal indireta classifica esses erros inequivocamente como casos de confabulação (falsídica). O conteúdo da 'lembrança' seria algo do tipo $1 x\left(P_{1} x \& P_{2} x \& \ldots \& P_{\mathrm{n}} x\right)$, em que os predicados $P_{1}, P_{2}, \ldots, P_{\mathrm{n}}$ representariam propriedades da face 'lembrada'. Não existe 'o $x$ ' tal que $P_{1} x \& P_{2} x \& \ldots \&$ $P_{\mathrm{n} x}$. Por isso, o conteúdo da 'lembrança' seria inacurado. Porém, exatamente porque não há 'o $x$ ' tal que $P_{1} x \& P_{2} x \& \ldots \& P_{\mathrm{n}} x$ (supondo que $x$ s imaginários não causam lembranças de indivíduos não-mentais), esse $x$ não pode ter causado a 'lembrança'. Resultado: confabulação (falsídica). De fato, nessa teoria todo caso de 'lembrança' incacurada é um caso de confabulação (não há 'o $x$ ' que possa causar a lembrança).

A conclusão, então, é a de que a dificuldade que a teoria causal tem de lidar com os casos de DRM, “perdido no shopping” e erro de conjunção de conteúdo deve-se mesmo ao critério causal. Num próximo artigo, pretendo investigar como construir uma teoria causal indireta cujo critério causal não resulte nesses problemas.

\section{Agradecimentos}

Ao Prof. Jaime Parera Rebello, que, além de ter me iniciado nas artes da memória e Filosofia da Linguagem, orientou a dissertação na qual esse artigo é baseado.

\section{Referências}

BERNECKER, S. The Metaphysics of Memory. Springer, 2008. 
BERNECKER, S. Memory: A Philosophical Study. Oxford University Press, 2010.

BERNECKER, S. A Causal Theory of Mnemonic Confabulation. Frontiers in Psychology, 8, 1207, 2017.

BERRIOS, G. Confabulations: A Conceptual History. Journal of the History of the Neurosciences, 7(3), 225-241, 1998.

BROWN, E., DEFFEnBACHER, K., \& STURGill, W. Memory for Faces and the Circumstances of Encounter. Journal of Applied Psychology, 62 (3), 311-318, 1977.

DALlA BARBA, G. Memory, Consciousness and Temporality. Neurobiological Foundation of Aberrant Behaviors. Springer, 2002.

DANTAS, D. Memória Incerta: Lembranças, Falsas Lembranças e as Ciências da Memória (dissertação de mestrado, Universidade Federal do Rio Grande do Sul), 2010.

DEESE, J. On the Prediction of Occurrence of Certain Verbal Intrusions in Free Recall. Journal of Experimental Psychology, 58, 17-22, 1959.

JOHNSON, M., FOLEY, M. \& LEACH, K. The Consequences for Memory of Imagining in another Person's Voice. Memory \& Cognition, 16(4), 337-342, 1988.

JOHnSON, M., HASHTROUDi, S. \& LINDSAY, D. Source Monitoring. Psychological Bulletin, 114(1), 3-28, 1993.

JOHNSON, M., RAYE, C., WANG, A. \& TAYLOR, T. Fact and Fantasy: The Roles of Accuracy and Variability. In. Confusing Imaginations with Perceptual Experiences. Journal of Experimental Psychology: Human Learning and Memory, 5(3), 229-240, 1979.

LEVINE, L. Reconstructing Memory for Emotions. Journal of Experimental Psychology: General, 126(2), 165-177, 1997.

LEWIS, D. Counterfactuals, Oxford: Blackwell, 1973.

LEWIS, D. Counterfactual Dependence and Time’s Arrow, Noûs, 13(4): 455-476, 1979.

LOFTUS, E. \& PICKRELL, J. The Formation of False Memories. Psychiatric Annals, 25(12), 720-725, 1995.

LOFTUS, E., COAN, J., \& PICKRELL, J. Manufacturing False Memories Using Bits of Reality. In. L. Reder (Ed.), Implicit memory and metacognition (Chap. 8, pp. 195-220), 1996.

MALCOLM, N. Memory and Mind. Cornell University Press, 1977.

MARTIN, C. \& DEUTSCHER, M. Remembering. Philosophical Review, 75, 161-96, 1966.

MICHAELIAN, K. Mental Time Travel: Episodic Memory and Our Knowledge of the Personal Past. MIT Press, 2016. 
MICHAELIAN, K. Confabulating, Misremembering, Relearning: The Simulation Theory of Memory and Unsuccessful Remembering. Frontiers in Psychology, 7, 1857, 2016.

REBELlo, J. Elementos para uma Análise do Recordar. Em Fonseca, Pohlmann \& Goldmeier (Eds.), Ética, Política e Esclarecimento Público: Ensaios em Homenagem a Nelson Boeira. Editora Bestiário, 2012.

REICHENBACH, H. The Direction of Time. University of California Press, 1956.

REINITZ, M., LAMMERS, W. \& COCHRAN, a. Memory-Conjunction Errors: Miscombination of Stored Stimulus Features Can Produce Illusions of Memory. Memory \& Cognition, 20(1), 1-11, 1992.

ROBINS, S. Misremembering. Philosophical Psychology, 29(3), 432-447, 2016.

ROBINS, S. Mnemonic Confabulation. Topoi. Disponível em: https://doi.org/10.1007/s11245-018-9613-x. Acesso em: 22 nov. 2019.

ROEDIGER, H. \& MCDERMOTT, K. Creating False Memories: Remembering Words Not Presented in Lists. Journal of Experimental Psychology: Learning, Memory, and Cognition, 21, 803-814, 1995.

SCHACTER, D. \& ADDIS, D. The Ghosts of Past and Future: A Memory That Works by Piecing Together Bits of The Past May Be Better Suited to Simulating Future Events Than One That Is A Store of Perfect Records. Nature, 445(7123), 27-27, 2007.

TULVING, E. Episodic Memory: From Mind to Brain. Annu Rev Psychology, 53, 1-25, 2002.

WhiteheAd, A. \& RUSSELL, B. Principia Mathematica. Cambridge University Press, 1910. 